\title{
QoS based Enhanced System Determination Plan for 4G Frameworks
}

\author{
G. Michael, C. Nalini, S. Pothumani
}

\begin{abstract}
In this paper we regulate $4 G$ structures where choice of applications in light of Rank of the separation work has been enlisted for different open associations/get to types of progress, dynamic clients to the degree handoff we moreover figure the data transmission, delay and no of gatherings lost. This client driven structure deals with the motivation to give best associations of the system to the clients. The proposed estimation shows better outcomes separated from single parameter based structure, under a heterogeneous structure framework. In like way in the last half we do consider the data move limit usage utilizing (SFF) and dynamic recently fit (DFF) by which we limit as far as possible which is an oblige for some client by prudence of adaptable controlling. At long last we look at the execution estimations by strategies for PC reenactment and multifaceted nature Rank in light of parcel work and Always Best Connected approach for gathering transport degree, throughput, no of packs lost and deferral.
\end{abstract}

Keywords: ABC(Always Best Connected), SFF(Static First Fit), DFF(Dynamic First Fit).

\section{INTRODUCTION}

In this paper we control flexible correspondence systems, after $2 \mathrm{G}$ and $3 \mathrm{G}$, the Fourth Generation $(4 \mathrm{G})$ was from the begin expected as ultra-smart broadband remote structure [1-5] using Orthogonal Frequency division multiplexing. Fundamentally the User driven point of view was appeared, instigating a fantasy of $4 \mathrm{G}$ and its key features and imaginative improvement. Also, $4 \mathrm{G}$ will be a connection stage giving clear inclinations to the degree move speed, scope, control use and range use. Regardless, to comprehend the above central focuses, each terminal contraption, used as a dash of $4 \mathrm{G}$ structures, need to help multi-mode, multi-access and reconfiguration limits. That is, each terminal can get to more than one sort of structure and possibly get to different frameworks at the same time for different applications (e.g., one for voice and another for getting spilling media). In such a condition, a terminal ought to most likely discover all structures that are available for use. A fundamentally intensely risky issue is to discover and pick the best structure at whatever point a handoff is head. To find with least idea accordingly speed with the help of Static First fit and Dynamic first fit [6-11].

Revised Manuscript Received on August 22, 2019.

G.Michael, Department of CSE, Bharath Institute of Higher Education and Research, Chennai, Tamilnadu, India.

C. Nalini, Department of CSE, Bharath Institute of Higher Education and Research, Chennai, Tamilnadu, India

S. Pothumani, Department of CSE, Bharath Institute of Higher Education and Research, Chennai, Tamilnadu, India.

\section{ALWAYS BEST CONNECTED (ABC)}

In the most recent decade a few remote access degrees of progress have made. Some of them are interfacing with, most are basic. Today obviously there won't be a solitary remote access structure fitting for all the application condition. Regardless of what might be standard, it is standard that a basic number of them will concur in heterogeneous remote access structures. Clients will get to the system structure through the best open strategy. This prompts the Always Best Related (ABC) thought. Beginning late, there has been much buzz about $\mathrm{ABC}$, regardless, a specific clarification of the thoughts included is starting in the no so distant past missing. Very are distinctive referencing holding tight for an answer. The first and most key respects the criticalness of best. Everything considered, which is the best procedure unmitigated relies on the application condition, on the stray pieces and on the point of view (e.g., the best in the client viewpoint does in no way, shape or form at all, at all mix with the best in the structure expert viewpoint). Client driven system a terminal ought to in all likelihood find all structures that are open for use and to find and pick the best structure at whatever point a handoff is head. In a client driven condition, versatility and direct part at the client level are central necessities for the general open to get the new movement [12-16].

\section{PROPOSED SYSTEM}

To use the pack work, all the parameter regards are sorted out with the objective that they go going toward respects in the level of zero and one. These traits are doled out with an authoritative objective that the higher the regard, better it is for the customer. Let $\mathrm{N}=\{$ net (1), net (2), net (3), net (m) $\}$ be the strategy of various structure choices available to the customer. The $\mathrm{n}$ degrees of customer customization parameters are would when all is said in done by set: $\mathrm{P}=\{\mathrm{p}$ (1), p (2), p (3) and p (n)\}. Thusly jth sort out in the set $\mathrm{N}$ is depicted by a methodology of parameter perspectives made as $\mathrm{Pj}=\{\mathrm{pj}(1), \mathrm{pj}(2), \mathrm{pj}(3), \mathrm{pj}(\mathrm{n})\}$. The structures in set $\mathrm{N}$ are managed in a referenced improvement concerning the parameters in set $\mathrm{P}$ as shown by the rudiments of customer $\mathrm{u}$ for the session $\mathrm{k}$. This referenced once-over is tended to as Xp where $p$ is a particular parameter in set P. Position of ith engineer in the referenced set is given by its condition in the set would all things considered as Rank (i,p,u,k). As this is a multi-parameter designing issue, a changed explanation of Borda's system for rank full scale [5] has been used as positional dealing with structure.

Referenced philosophies of open structures got before in this segment have been used to

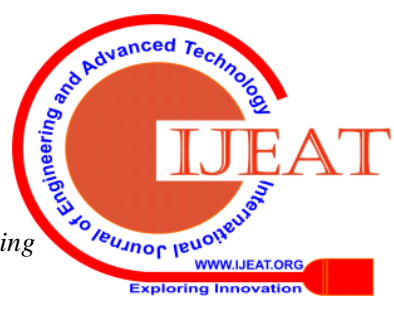


dole out a score to every framework identifying with its condition in the referenced records over each parameter in set $\mathrm{P}$. Each structure is, thusly, having a set or $\mathrm{n}$ scores, each showing up contrastingly in relationship with a parameter. Which can pick the structure routinely in setting on a changed sort out decision procedure concerning handoff which will simultaneously be connected with any framework without be meddled [17-18].

\section{A. STATIC FIRST-FIT ALGORITHM (SFF)}

Static first-fit sorts officials and irregularities in rising ideas of their transmission cutoff space degrees. Each refinement (in rising referencing) is doled out to the rule go between (other than in climbing request) that has satisfying space to store this sales. On the off chance that this center individual has elegant data move capacity to benefit this sales, the isolating level of transmission reason for control is held at the authority, and what makes a difference is removed from the un-set away sales pool. Obviously, if the administrator does not have tasteful data transmission to benefit the consistent irregularity, the open trade speed at the official is spared something for this requesting. The test is returned a little while later into the un-set away sales pool with the saved data transmission subtracted from its required trade speed. The go-between is removed from the go between pool since a large portion of its data transmission has been depleted [19-23].

\section{B. DYNAMIC FIRST-FIT ALGORITHM (DFF)}

DFF takes after SFF, clearly, incredibly the exchange speed space level of a section judge is recomputed after an article is set onto that middle individual and go-betweens are turn by their new information transmission space degrees (in SFF, the degree is dealt with only once, toward the begin). The sense behind DFF is that the proper transmission most extreme space level of a middle individual changes after an article is verified, and re dealing with this degree may comprehend a common rule talking placement[24-30].

\section{RESULT AND DISCUSSION}

Tool: Network Simulator (NS - 2)

Topology: Wireless

Scheduling Algorithms: Drop tail

Transport protocols: TCP, UDP

Routing: static and dynamic

Application: CBR, traffic generator

Routing protocol: Any cast service in $4 \mathrm{G}$ networks

\section{TOPOLOGIES USED}

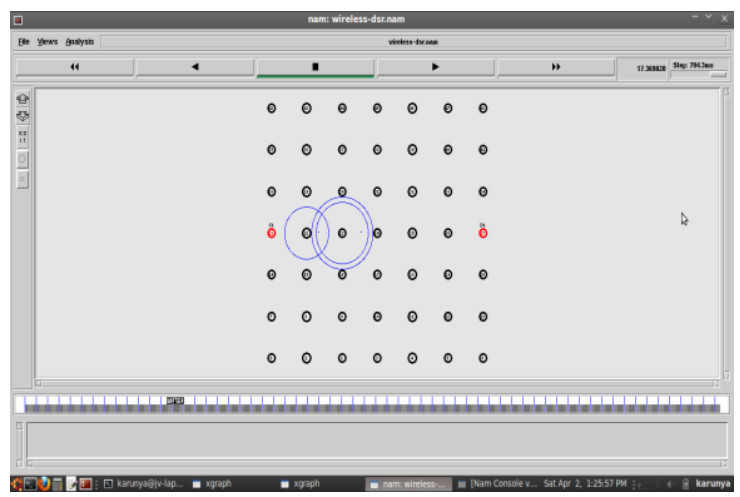

Fig 1: The framework topology dependent on static steering. since the steering table components

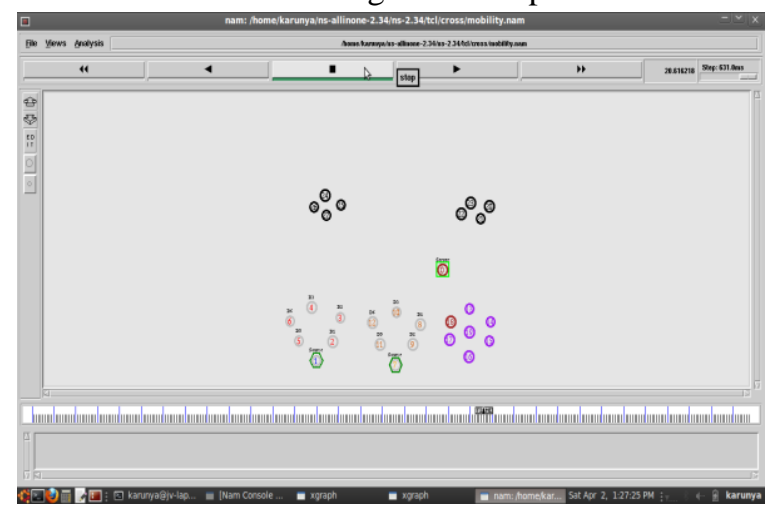

Fig 2: The versatility topology dependent on powerful steering. since the steering table components does not exits so we need to default directing.

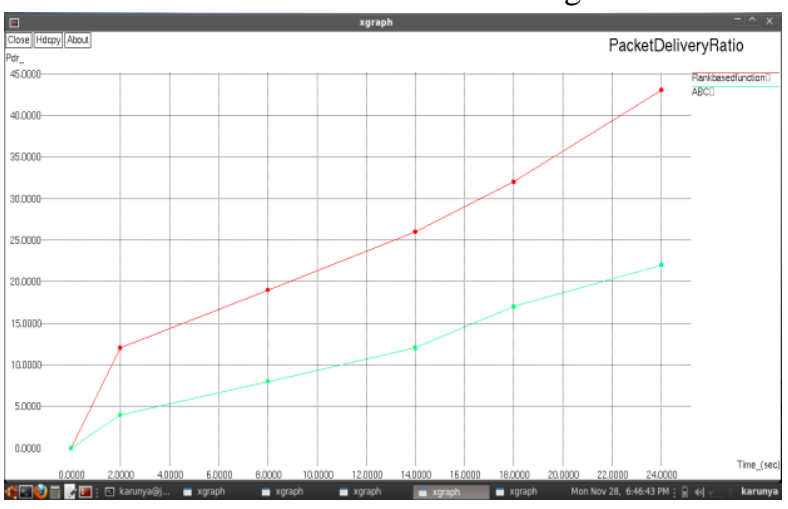

Fig 3: The parcel conveyance proportion acquired better outcomes for rank based separation capacity contrasted with $\mathrm{ABC}$.

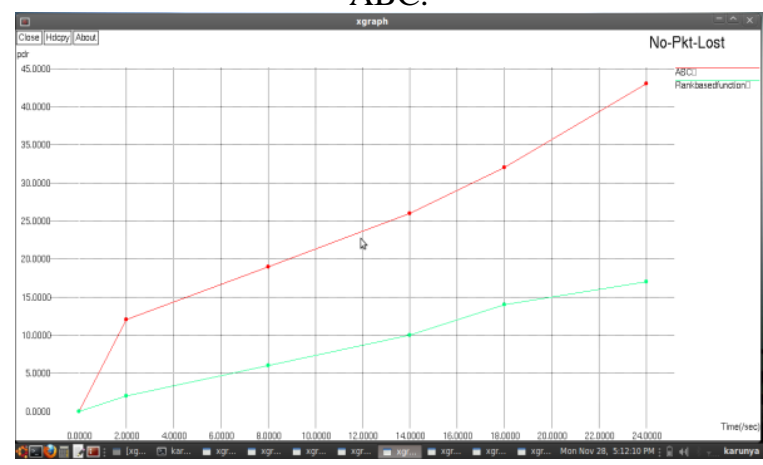

Fig 4: The all out no of bundles lost because of impedance, blockage. it implies the rank based capacity yields preferable execution over $\mathrm{ABC}$. 


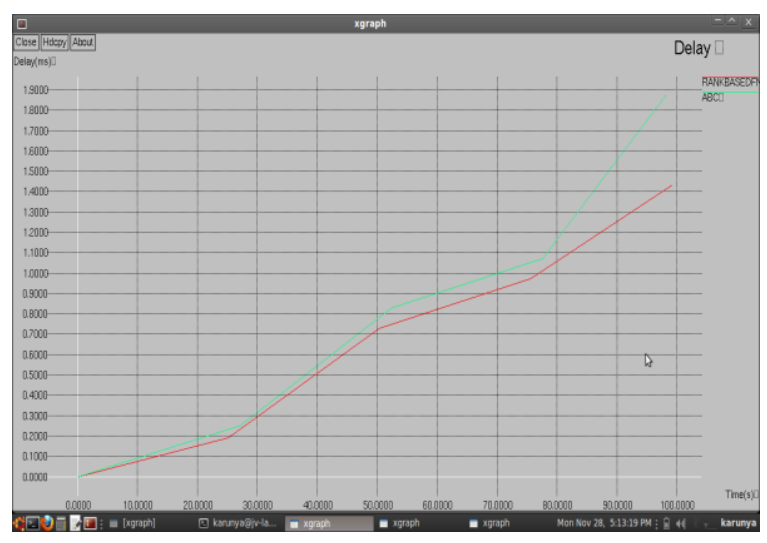

Fig 5: the time interim between first parcel and second packet.it implies that rank based capacity yields preferred execution over ABC.

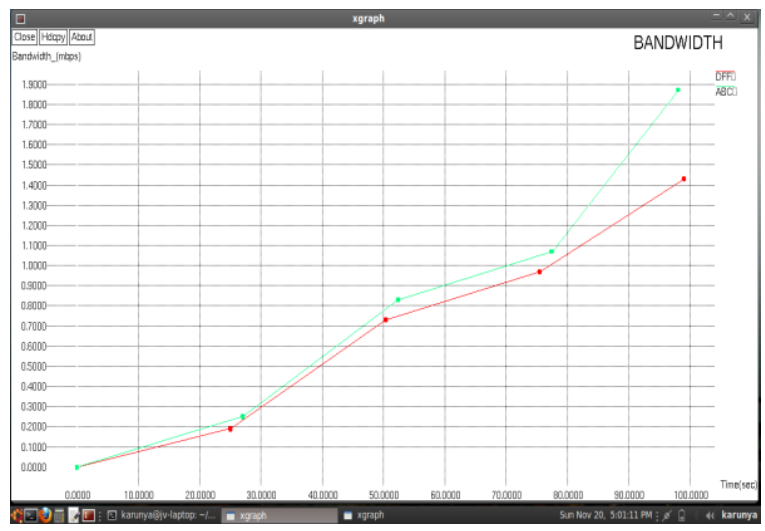

Fig 6: The general transfer speed gotten by ascertaining the information limit of a connection utilizing dff is decreased significant than $\mathrm{ABC}$.

\section{CONCLUSION}

Thusly in this investigation we oversee $4 \mathrm{G}$ frameworks and consider its execution estimations for static and dynamic frameworks by methods for PC diversion using ns 2 and find out transmission limit, delay and no of groups lost and infer that position in light of division work with Static First Fit and Dynamic First Fit yields favored execution over the past techniques of $\mathrm{ABC}$ and Client driven Approach.

\section{REFERENCES}

[1] Gowri Sankaran, B., Karthik, B. \& Vijayaragavan, S.P. 2019, "Weight ward change region plummeting change for square based image huffman coding", International Journal of Innovative Technology and Exploring Engineering, vol. 8, no. 10, pp. 4313-4316.

[2] Gowri Sankaran, B., Karthik, B. \& Vijayaragavan, S.P. 2019, "Image compression utilizing wavelet transform", International Journal of Innovative Technology and Exploring Engineering, vol. 8, no. 10, pp. 4305-4308.

[3] Kandavel, N. \& Kumaravel, A. 2019, "Offloading computation for efficient energy in mobile cloud computing", International Journal of Innovative Technology and Exploring Engineering, vol. 8, no. 10, pp. 4317-4320.

[4] Vinoth, V.V. \& Kanniga, E. 2019, "Reversible data hiding in encrypting images-an system", International Journal of Engineering and Advanced Technology, vol. 8, no. 6, pp. 3051-3053.

[5] Selvapriya, B. \& Raghu, B. 2019, "Pseudocoloring of medical images: A research", International Journal of Engineering and Advanced Technology, vol. 8, no. 6, pp. 3712-3716.

[6] Senthil Kumar, K. \& Muthukumaravel, A. 2019, "Bi-objective constraint and hybrid optimizer for the test case prioritization", International Journal of Engineering and Advanced Technology, vol. 8, no. 6 , pp. 3436-3448.
[7] Kavitha, G., Priya, N., Anuradha, C. \& Pothumani, S. 2019 , "Read-write, peer-to-peer algorithms for the location-identity split", International Journal of Innovative Technology and Exploring Engineering, vol. 8, no. 9 Special Issue 3, pp. 445-447.

[8] Kaliyamurthie, K.P., Michael, G., Anuratha, C. \& Sundaraj, B. 2019 "Certain improvements in alzheimer disease classification using novel fuzzy c means clustering for image segmentation", International Journal of Innovative Technology and Exploring Engineering, vol. 8, no. 9 Special Issue 3, pp. 599-604.

[9] Kaliyamurthie, K.P., Sundarraj, B., Geo, A.V.A. \& Michael, G. 2019 "RIB: Analysis of I/O automata", International Journal of Innovative Technology and Exploring Engineering, vol. 8, no. 9 Special Issue 3, pp. 1019-1022.

[10] Velvizhi, R., Rajabhushanam, C. \& Vidhya, S.R.S. 2019, "Opinion mining for travel route recommendation using Social Media Networks (Twitter)", International Journal of Innovative Technology and Exploring Engineering, vol. 8, no. 9 Special Issue 3, pp. 508-512.

[11] Kavitha, R., Sangeetha, S. \& Varghese, A.G. 2019, "Human activity patterns in big data for healthcare applications", International Journal of Innovative Technology and Exploring Engineering, vol. 8, no. 9 Special Issue 3, pp. 1101-1103.

[12] Pothumani, S., Anandam, A.K., Sharma, N. \& Franklin, S. 2019, "Extended VEOT framework - Implemented in a smart boutique", International Journal of Innovative Technology and Exploring Engineering, vol. 8, no. 9 Special Issue 3, pp. 762-767.

[13] Kaliyamurthie, K.P., Michael, G., Krishnan, R.M.V. \& Sundarraj, B. 2019, "Pseudorandom techniques for the internet", International Journal of Innovative Technology and Exploring Engineering, vol. 8, no. 9 Special Issue 3, pp. 915-918.

[14] Aravindasamy, R., Jeffrin Rajan, M., Rama, A. \& Kavitha, P. 2019, "Deep learning provisions in the matlab: Focus on CNN facility", International Journal of Innovative Technology and Exploring Engineering, vol. 8, no. 9 Special Issue 3, pp. 990-994.

[15] Theivasigamani, S., Linda, M. \& Amudha, S. 2019, "Object sensing and its identification \& motion sensing", International Journal of Innovative Technology and Exploring Engineering, vol. 8, no. 9 Special Issue 3, pp. 545-549.

[16] Mary Linda, I., Vimala, D. \& Shanmuga Priya, K. 2019, "A methodology for the emulation of IPv4", International Journal of Innovative Technology and Exploring Engineering, vol. 8, no. 9 Special Issue 3, pp. 848-852.

[17] Velvizhi, R., Priya, D.J., Vimala, D. \& Linda, I.M. 2019, "Increased routing algorithm for mobile adhoc networks", International Journal of Innovative Technology and Exploring Engineering, vol. 8, no. 9 Special Issue 3, pp. 1606-1608.

[18] Sangeetha, S., Anuradha, C. \& Priya, N. 2019, "DNS in real world", International Journal of Innovative Technology and Exploring Engineering, vol. 8, no. 9 Special Issue 3, pp. 937-940.

[19] Geetha, C., Vimala, D. \& Priya, K.S. 2019, "Constructing multi-processors and spreadsheets with SKIVE", International Journal of Innovative Technology and Exploring Engineering, vol. 8, no. 9 Special Issue 3, pp. 516-519.

[20] Yugendhar, K., Sugumar, V. \& Kavitha, P. 2019, "A novel method of univac using fuzzy logic", International Journal of Innovative Technology and Exploring Engineering, vol. 8, no. 9 Special Issue 3, pp. 435-437.

[21] Kaliyamurthie, K.P., Michael, G., Elankavi, R. \& Jijo, S.A. 2019 , "Implementing aggregate-key for sharing data in cloud environment using cryptographic encryption", International Journal of Innovative Technology and Exploring Engineering, vol. 8, no. 9 Special Issue 3, pp. 957-959.

[22] Jeffrin Rajan, M., Aravindasamy, R., Kavitha, P. \& Rama, A. 2019, "A novel method of object orientation variation in $\mathrm{C}++$ and java", International Journal of Innovative Technology and Exploring Engineering, vol. 8, no. 9 Special Issue 3, pp. 708-710.

[23] Nayak, R., Dinesh, S. \& Thirunavukkarasu, S. 2019, "A novel method improvement of rapid miner for the data mining applications", International Journal of Innovative Technology and Exploring Engineering, vol. 8, no. 9 Special Issue 3, pp. 457-460.

[24] Sivaraman, K., Krishnan, R.M.V., Sundarraj, B. \& Sri Gowthem, S. 2019, "Network failure detection and diagnosis by analyzing syslog and SNS data: Applying big data analysis to network operations", International Journal of Innovative Technology and Exploring Engineering, vol. 8, no. 9 Special Issue 3, pp. 883-887.

[25] Vimala, D., Linda, I.M. \& Priya, K.S. 2019, "Decoupling online algorithms from erasure coding in DNS", International Journal

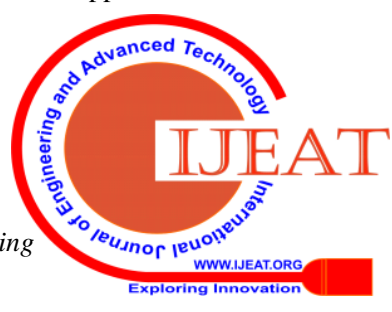


of Innovative Technology and Exploring Engineering, vol. 8, no. 9 Special Issue 3, pp. 950-953.

[26] Rama, A., Kumaravel, A. \& Nalini, C. 2019, "Preprocessing medical images for classification using deep learning techniques", International Journal of Innovative Technology and Exploring Engineering, vol. 8, no. 9 Special Issue 3, pp. 711-716.

[27] Sangeetha, S., Srividhya, S.R., Anita Davamani, K. \& Amudha, S. 2019, "A procedure for avoid overrun error in universal synchronous asynchronous receiver transmitter (usart) by utilizing dummy join and interrupt latency method", International Journal of Innovative Technology and Exploring Engineering, vol. 8, no. 9 Special Issue 3, pp. 657-660.

[28] Aravindasamy, R., Jeyapriya, D., Sundarajan, B. \& Sangeetha, S. 2019, "Data duplication in cloud for optimal performance and security", International Journal of Innovative Technology and Exploring Engineering, vol. 8, no. 9 Special Issue 3, pp. 1156-1158.

[29] Aravindasamy, R., Jeffrin Rajan, M., Sugumar, V. \& Kavitha, P. 2019 "A novel method on developing superblocks and the transistor using apodryal", International Journal of Innovative Technology and Exploring Engineering, vol. 8, no. 9 Special Issue 3, pp. 982-985.

[30] Sasikumar, C.S. \& Kumaravel, A. 2019, "E-learning attributes selection through rough set theory and data mining", International Journal of Innovative Technology and Exploring Engineering, vol. 8, no. 10 , pp. 3920-3924.

\section{AUTHORS PROFILE}

G.Michael, Associate Professor, Department of Computer Science \& Engineering, Bharath Institute of Higher Education and Research, Chennai, India Science \& Engineering, Bharath Institute of Higher Education and Research, Chennai, India

S. Pothumani Assistant Professor, Department of Computer Science \& Engineering, Bharath Institute of Higher Education and Research, Chennai, India 